\title{
Application of positive end expiratory pressure during laparoscopic surgery
}

\author{
Hong-Beom Bae
}

Department of Anesthesiology and Pain Medicine, Chonnam National University Medical School, Gwangju, Korea

Positive-pressure ventilation during general anesthesia is a prerequisite for numerous surgical conditions. Mechanical ventilation is non-physiological and can induce lung injury, although ventilator-induced lung injury may be of minor clinical importance during anesthesia for most patients with healthy lungs. However, growing evidence suggests that lung injury can be initiated by mechanical ventilation with a low tidal volume as well as with a high tidal volume in animal models of healthy lungs [1-4]. These recent data suggest that ventilation strategies to minimize lung stress (e.g., prevention of repeated closure and opening) improve oxygenation and can reduce lung injury during general anesthesia. A previous study demonstrated that atelectasis rapidly develops after the induction of anesthesia with a high oxygen fraction, which can be effectively resolved by a lung recruitment maneuver and subsequent application of a substantial level of positive end-expiratory pressure (PEEP) [5].

Increase in shunt and low ventilation to perfusion after the induction of general anesthesia are due to alterations in the shape and dimension of the thoracic cage, which result in reductions in the functional residual capacity (FRC) and pulmonary compliance and an increase in airway resistance [6,7]. The cephalad movement and reduced activity of the diaphragm in the supine position promote the formation of compression atelectasis in the dependent portion of the lung. In addition, the decreased lung volume increases the ratio of the closing capacity to FRC during general anesthesia, which may increase cyclic alveolar closure and reopening during mechanical ventilation. In particular, the increase in abdominal pressure caused by pneumoperitoneum and the head-down body position during laparoscopic surgery causes an additional cranial shift in the end-expiratory position of the diaphragm and enhances airway closure and atelectasis formation in the dependent lung regions [8].

The application of PEEP is believed to preserve lung structures and decrease cyclic closure and reopening of alveoli [9], although there is insufficient evidence regarding whether intraoperative PEEP improves postoperative mortality and respiratory complications [10]. A previous study found that application of a constant PEEP of $5 \mathrm{cmH}_{2} \mathrm{O}$ improves arterial oxygenation compared with zero end-expiratory pressure during endoscopic robot-assisted radical prostatectomy [11]. Lee et al. [12] also suggested use of different levels of PEEP and that the application of a PEEP of $7 \mathrm{cmH}_{2} \mathrm{O}$ improved arterial oxygenation without excessive peak airway pressure or depression of hemodynamic parameters during endoscopic robot-assisted radical prostatectomy. These results should be interpreted carefully in terms of the application of PEEP in overall laparoscopic surgery because various factors, such as body position during laparoscopic surgery and obesity, may affect respiratory function and arterial oxygenation. Previous studies have shown that pneumoperitoneum could increase arterial oxygen tension despite an increase in atelectasis $[13,14]$, and a PEEP of $10 \mathrm{cmH}_{2} \mathrm{O}$ alone did not improve end-expiratory lung volume or oxygenation during laparoscopic surgery requiring the reverse Trendelenburg position [15]. PEEP alone did not reduce atelectasis or improve oxygenation in morbidly obese patients [16].

The ideal level of PEEP has been thought to exist above the lower inflection point (LIP), which can be obtained from the overall pressure-volume curve; however, the LIP indicates the pressure at which recruitment of the lung begins, not that at

Corresponding author: Hong-Beom Bae, M.D., Ph.D., Department of Anesthesiology and Pain Medicine, Chonnam National University Medical School, 5, Hak-dong, Gwangju 501-746, Korea. Tel: 82-62-220-6895, Fax: 82-62-232-6294, E-mail: nextphil2@jnu.ac.kr

(c) This is an open-access article distributed under the terms of the Creative Commons Attribution Non-Commercial License (http:// creativecommons.org/licenses/by-nc/3.0/), which permits unrestricted non-commercial use, distribution, and reproduction in any medium, provided the original work is properly cited. 
which lung collapse begins. Although the application of a high airway pressure of $30 \mathrm{cmH}_{2} \mathrm{O}$ can significantly recruit collapsed lung, hyperinflation of the lungs by a vital capacity is need to ensure complete opening of the collapsed lung (airway pressure of $40 \mathrm{~cm} \mathrm{H}_{2} \mathrm{O}$ in patients of normal weight) [6]. Recently, as one approach to reopen the collapsed lung, a recruiting maneuver (RM) followed by the application of PEEP involving the application of $40 \mathrm{~cm} \mathrm{H}_{2} \mathrm{O}$ of continuous positive airway pressure for $40 \mathrm{~s}$ has been suggested to effectively re-expand the collapsed lung and improve oxygenation and respiratory mechanics in laparoscopic surgery as well as acute respiratory distress syndrome [15,17]. Another lung recruitment method involving high PEEP to reduce RM-induced negative cardiac effects has been investigated in cardiac surgery [18].
These open lung strategies appear to be helpful in terms of reducing the potential for ventilator-induced lung injury as a result of cyclic closing and opening of the lung in the intraoperative period. The development of atelectasis during general anesthesia does not appear to increase perioperative complications in most cases because the deep breathing and coughing encouraged by the medical service team after anesthesia can effectively re-expand collapsed lungs. However, efforts to decrease the formation of atelectasis during general anesthesia may be beneficial because some atelectasis may still exist after the operation and become a site of infection [19]. Taken together, these recent data suggest that adequate PEEP and RM can improve arterial oxygenation and respiratory mechanics during anesthesia.

\section{References}

1. Reiss LK, Kowallik A, Uhlig S. Recurrent recruitment manoeuvres improve lung mechanics and minimize lung injury during mechanical ventilation of healthy mice. PLoS One 2011; 6: e24527.

2. Hegeman MA, Hemmes SN, Kuipers MT, Bos LD, Jongsma G, Roelofs JJ, et al. The extent of ventilator-induced lung injury in mice partly depends on duration of mechanical ventilation. Crit Care Res Pract 2013; 2013: 435236.

3. Vaneker M, Halbertsma FJ, van Egmond J, Netea MG, Dijkman HB, Snijdelaar DG, et al. Mechanical ventilation in healthy mice induces reversible pulmonary and systemic cytokine elevation with preserved alveolar integrity: an in vivo model using clinical relevant ventilation settings. Anesthesiology 2007; 107: 419-26.

4. Wolthuis EK, Vlaar AP, Choi G, Roelofs JJ, Juffermans NP, Schultz MJ. Mechanical ventilation using non-injurious ventilation settings causes lung injury in the absence of pre-existing lung injury in healthy mice. Crit Care 2009; 13: R1.

5. Neumann P, Rothen HU, Berglund JE, Valtysson J, Magnusson A, Hedenstierna G. Positive end-expiratory pressure prevents atelectasis during general anaesthesia even in the presence of a high inspired oxygen concentration. Acta Anaesthesiol Scand 1999; 43: 295-301.

6. Wahba RM. Airway closure and intraoperative hypoxaemia: twenty-five years later. Can J Anaesth 1996; 43: 1144-9.

7. Bruells CS, Rossaint R. Physiology of gas exchange during anaesthesia. Eur J Anaesthesiol 2011; 28: 570-9.

8. Fahy BG, Barnas GM, Flowers JL, Nagle SE, Njoku MJ. The effects of increased abdominal pressure on lung and chest wall mechanics during laparoscopic surgery. Anesth Analg 1995; 81: 744-50.

9. Rusca M, Proietti S, Schnyder P, Frascarolo P, Hedenstierna G, Spahn DR, et al. Prevention of atelectasis formation during induction of general anesthesia. Anesth Analg 2003; 97: 1835-9.

10. Imberger G, McIlroy D, Pace NL, Wetterslev J, Brok J, Møller AM. Positive end-expiratory pressure (PEEP) during anaesthesia for the prevention of mortality and postoperative pulmonary complications. Cochrane Database Syst Rev 2010; 9: CD007922.

11. Meininger D, Byhahn C, Mierdl S, Westphal K, Zwissler B. Positive end-expiratory pressure improves arterial oxygenation during prolonged pneumoperitoneum. Acta Anaesthesiol Scand 2005; 49: 778-83.

12. Lee HJ, Kim KS, Jeong JS, Shim JC, Cho ES. Optimal positive end-expiratory pressure during robot-assisted laparoscopic radical prostatectomy. Korean J Anesthesiol 2013; 65: 245-51.

13. Andersson LE, Bååth M, Thörne A, Aspelin P, Odeberg-Wernerman S. Effect of carbon dioxide pneumoperitoneum on development of atelectasis during anesthesia, examined by spiral computed tomography. Anesthesiology 2005; 102: 293-9.

14. Andersson L, Lagerstrand L, Thörne A, Sollevi A, Brodin LA, Odeberg-Wernerman S. Effect of CO(2) pneumoperitoneum on ventilationperfusion relationships during laparoscopic cholecystectomy. Acta Anaesthesiol Scand 2002; 46: 552-60.

15. Futier E, Constantin JM, Pelosi P, Chanques G, Kwiatkoskwi F, Jaber S, et al. Intraoperative recruitment maneuver reverses detrimental pneumoperitoneum-induced respiratory effects in healthy weight and obese patients undergoing laparoscopy. Anesthesiology 2010; 113: 1310-9.

16. Reinius H, Jonsson L, Gustafsson S, Sundbom M, Duvernoy O, Pelosi P, et al. Prevention of atelectasis in morbidly obese patients during general anesthesia and paralysis: a computerized tomography study. Anesthesiology 2009; 111: 979-87.

17. Cinnella G, Grasso S, Spadaro S, Rauseo M, Mirabella L, Salatto P, et al. Effects of recruitment maneuver and positive end-expiratory pressure on respiratory mechanics and transpulmonary pressure during laparoscopic surgery. Anesthesiology 2013; 118: 114-22.

18. Celebi S, Köner O, Menda F, Korkut K, Suzer K, Cakar N. The pulmonary and hemodynamic effects of two different recruitment maneuvers after cardiac surgery. Anesth Analg 2007; 104: 384-90.

19. van Kaam AH, Lachmann RA, Herting E, De Jaegere A, van Iwaarden F, Noorduyn LA, et al. Reducing atelectasis attenuates bacterial growth and translocation in experimental pneumonia. Am J Respir Crit Care Med 2004; 169: 1046-53. 